Comparison of the erythrocyte

sedimentation rate measured in the eye casualty department by the Seditainer method with an automated system

A.C. Browning

P.R. Hodgkins

Southampton Eye Unit Southampton General Hospital

Southampton, UK

\section{A.A. Burbidge}

Rheumatology Department Southampton General

Hospital

Southampton, UK

Mr A.C. Browning

Department of

Ophthalmology

B Floor

South Block

University Hospital Queen's Medical Centre Nottingham NG7 2UH, UK

Fax: +44(0)1159709963

Received: 11 May 1999 Accepted in revised form: 3 August 1999

\section{Abstract}

Purpose To compare a new automated system for the measurement of erythrocyte sedimentation rate (ESR) with the established manual Seditainer method.

Methods Two hundred and twelve patients undergoing investigation for giant cell arteritis or other systemic vasculitides had ESR measurements by both the established manual Seditainer and the new laboratory-based automated system. The results were compared by correlation coefficient and mean difference. The limits of agreement with confidence intervals were also calculated.

Results Across the range of results from 1 to $120 \mathrm{~mm} / \mathrm{h}$, the correlation coefficient was 0.844 . The automated method had a mean negative bias of $-9.8 \mathrm{~mm} / \mathrm{h}(95 \%$ confidence interval: -12.2 to $-7.4 \mathrm{~mm} / \mathrm{h}$ ). The wide scatter of results produced limits of agreement $( \pm 2$ standard deviations) between the two methods of -45 to $26 \mathrm{~mm} / \mathrm{h}$. There were seven results that were underestimated by the automated system which were clinically significant. Conclusions There is a wide degree of scatter between the two sets of results. The automated system has a negative bias when compared with the manual method. There is a propensity for the automated system to sporadically underestimate the true result, sometimes to a degree that is clinically significant. The authors therefore cannot recommend replacement of the manual Seditainer system at the present time.

Key words Seditainer, Automated ESR, Westergren, Giant cell arteritis

Associated with any inflammation there is an augmented hepatic synthesis of certain proteins and a resulting increase in their plasma
A.C. BROWNING, A.A. BURBIDGE, P.R. HODGKINS concentrations. There are dramatic rises in the plasma levels of C-reactive protein and serum amyloid A, with lesser rises in serum haptoglobin, complement proteins, caeruloplasmin and fibrinogen. This is termed the acute phase response. These changes are thought to be mediated by the release of interleukin- 6 from monocytes and their macrophage derivatives, which in turn leads to the production of prostaglandin $\mathrm{E}_{2}$ and interleukin-1. ${ }^{1}$

The erythrocyte sedimentation rate (ESR) is frequently used by ophthalmologists to assist in the diagnosis and management of giant cell arteritis. ${ }^{2,3}$ The ESR is a measure of the rate of fall of red cells in a tube and it reflects an increase in the plasma concentration of large proteins such as fibrinogen. The proteins cause rouleaux formation which, because of their greater density, gravitate downwards much faster than individual cells. The measurement can be performed using instruments in a nearpatient environment, allowing more rapid diagnosis (Ves-matic system, Diesse, 500200 Sambuca/Florence, Italy). The American College of Rheumatologists include an ESR (Westergren) of greater than $50 \mathrm{~mm} / \mathrm{h}$ as part of their diagnostic criteria for giant cell arteritis, along with localised headache, temporal artery tenderness, age greater than 50 years and a positive temporal artery biopsy. ${ }^{4}$ The accurate measurement of the ESR is therefore important for correct patient management.

The selected method of the International Committee for Standards in Haematology for measuring ESR is that of Westergren, dating back to $1921 .^{5}$ However, recent awareness of the biohazard risk associated with needles and phlebotomy has led to the development of vacuum aspiration and dilution systems to reduce operator exposure to blood and to simplify the assay procedure. An example of 
this is the manual Seditainer system, which shows excellent correlation with the Westergren method and is currently established in the eye casualty department for near-patient testing. ${ }^{6,7}$

Recently, a number of new automated ESR methods have become available which offer results within $25 \mathrm{~min}$ of venepuncture, combined with the added benefit of reduced operator workload. ${ }^{8,9}$ These are available in both laboratory and near-patient formats.

Before the automated system could replace the current Seditainer method, it was decided to compare the ESR results obtained using the new laboratory-based automated system with the established eye-casualtybased manual Seditainer system.

\section{Methods}

The Seditainer system comprises a glass vacuum tube measuring $120 \mathrm{~mm} \times 10.25 \mathrm{~mm}$. The tube contains $1.25 \mathrm{~cm}^{3}$ of $0.105 \mathrm{M}$ buffered sodium citrate and has a vacuum sufficient to draw $5.0 \mathrm{~cm}^{3}$ of blood. After the tube is filled to the required level, as marked on the tube, it is inverted 8-10 times to ensure thorough mixing. The tube is then immediately placed in a precalibrated Seditainer rack and left for exactly $1 \mathrm{~h}$. The ESR is then read directly from the precalibrated scale and this is equivalent to the Westergren ESR.

The automated system comprises a $100 \mathrm{~mm}$ evacuated glass collection tube containing $0.45 \mathrm{~cm}^{3}$ of $0.105 \mathrm{M}$ buffered sodium citrate. The tube is filled by vacuum with $1.8 \mathrm{~cm}^{3}$ of blood and sent immediately to the haematology laboratory. On arrival, the tube is placed in the instrument rack of the measuring device. The blood tube is mixed automatically for $5 \mathrm{~min}$ and placed at an angle of $20^{\circ}$ from the vertical. The tube is observed by means of a movable camera inside the instrument connected to a microprocessor. The computer records the changes in the height of the red cell column by measuring light transmission differences between sedimented cells and the overlying plasma. After $20 \mathrm{~min}$ the system reads the fall of the red cell column and converts it to the equivalent Westergren ESR measurement at $1 \mathrm{~h}$.

Venous blood was collected from 212 patients (156 women, 56 men; age range 18-96 years) attending the eye department or the rheumatology department with a suspected or proven diagnosis of giant cell arteritis or other type of systemic vasculitis. The ESR was measured immediately in the eye casualty department by either a doctor or an experienced nurse using the manual Seditainer system. Simultaneously blood was sent to the laboratory for measurement of ESR by the automated system.

The data were analysed using the techniques suggested by Bland and Altman. ${ }^{10}$ The two sets of ESR values were plotted as a scattergram and the correlation coefficient calculated. In addition, the mean of the ESR results from the two different methods was plotted against the difference between each set of results. This allowed a representation of any underlying disagreement between the methods or bias. The numerical differences between each set of data were expressed as the limits of agreement between the methods and the confidence intervals were calculated for the upper and lower limits of agreement.

\section{Results}

The paired ESR results for each patient were plotted as a scattergram (Fig. 1). There was a correlation coefficient of 0.844 . At high ESR values $(>70 \mathrm{~mm} / \mathrm{h}$ by the Seditainer method) scatter increased dramatically between the two

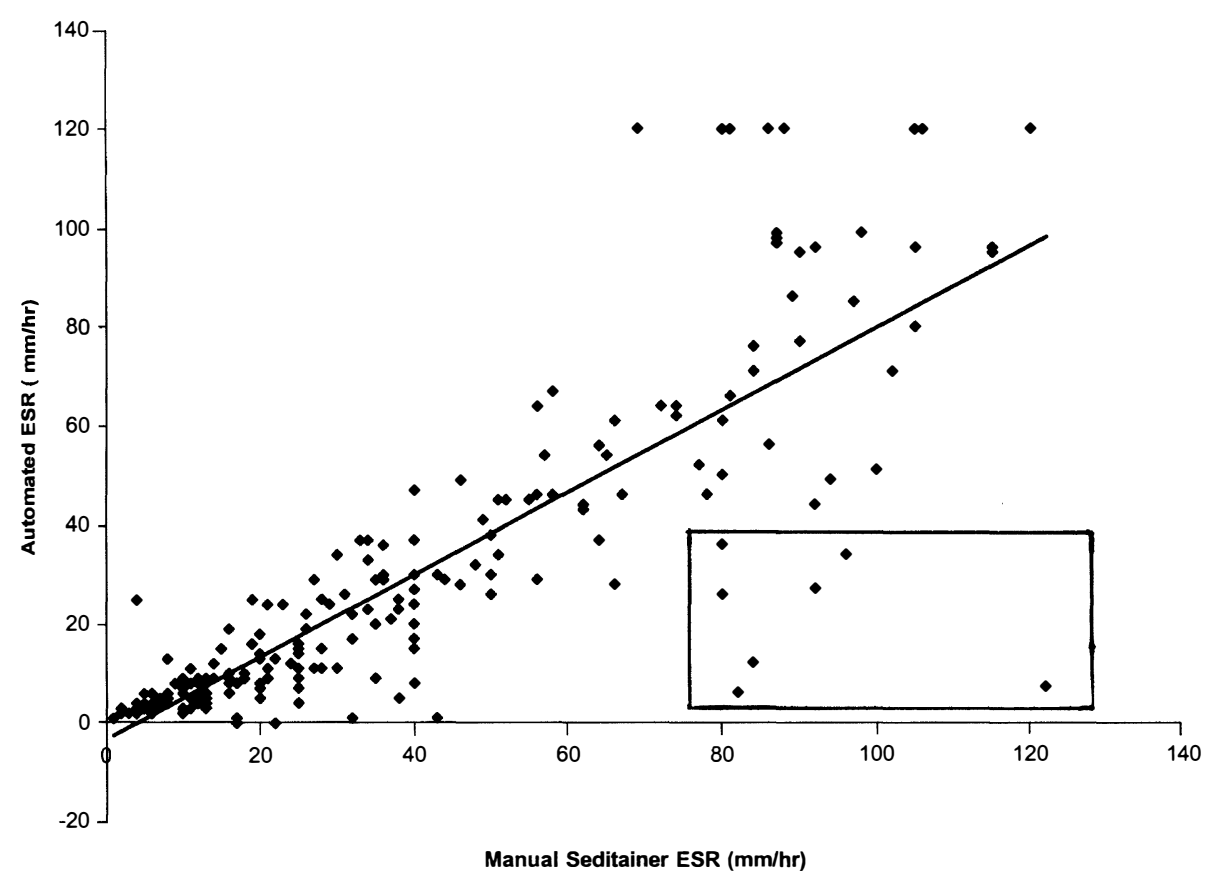

Fig. 1. Scattergram of ESR results obtained by the two analytical methods. Results deemed clinically significant are within the box. 


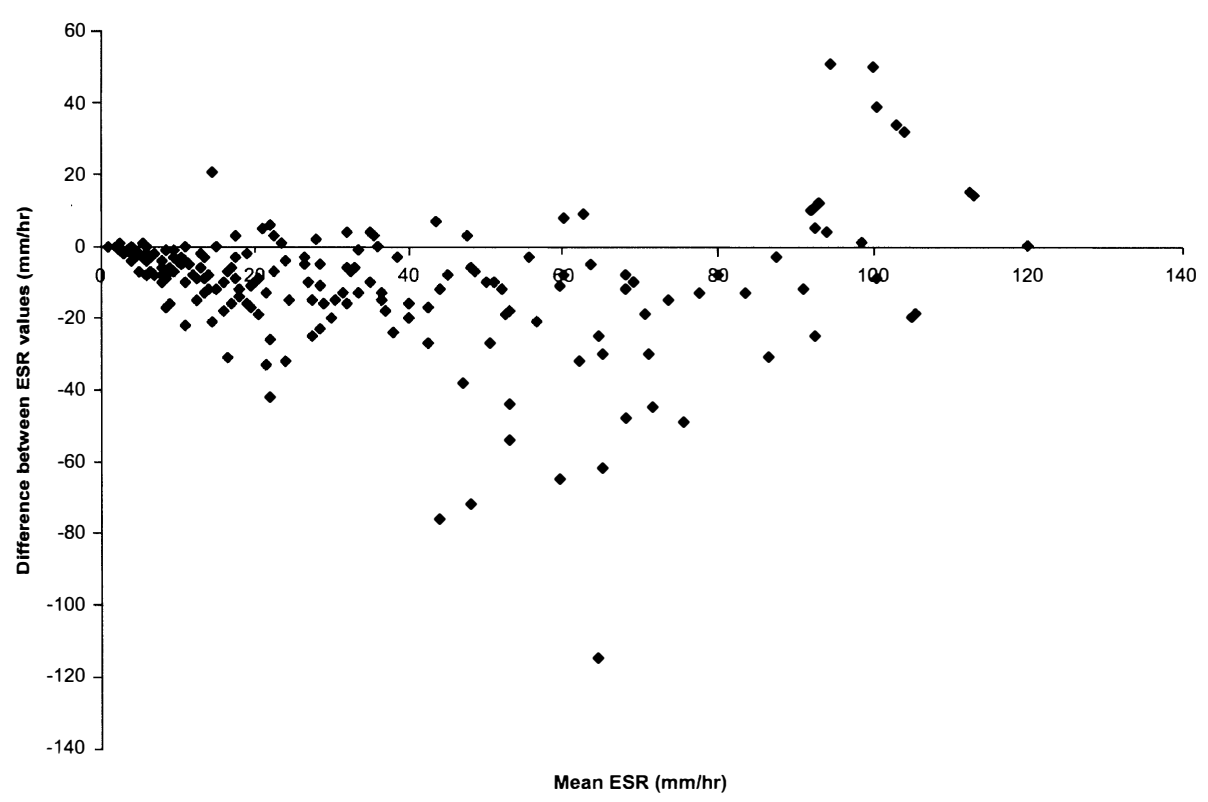

Fig. 2. The mean ESR result for each patient plotted against the difference between the automated and manual methods.

sets of data. There were seven significantly elevated results as determined by the Seditainer method that were reported as being within the normal range by the automated system $(<30 \mathrm{~mm} / \mathrm{h})$, as highlighted in Fig. 1 . For these seven patients, another blood sample was drawn within $24 \mathrm{~h}$ and the analysis was repeated. In all cases the elevated Seditainer result was found to be replicated, whereas the automated result was not. These discrepancies occurred at random times throughout the study.

The automated system showed a mean difference of $-9.8 \mathrm{~mm} / \mathrm{h}$ when compared with the Seditainer results across the range of results from 0 to $120 \mathrm{~mm} / \mathrm{h}(\mathrm{SD}=17.6$ $\mathrm{mm} / \mathrm{h} ; 95 \%$ confidence interval: -12.2 to $-7.4 \mathrm{~mm} / \mathrm{h}$ ). The limits of agreement ( \pm 2 standard deviations) between the methods range from $45 \mathrm{~mm} / \mathrm{h}$ below $(95 \%$ confidence interval: -49.1 to $-40.9 \mathrm{~mm} / \mathrm{h}$ ) to $26 \mathrm{mmh}$ above ( $95 \%$ confidence interval: +21.9 to $+30.1 \mathrm{~mm} / \mathrm{h}$ ) a given result measured by the Seditainer method. Fig. 2 shows the difference between each set of results plotted against the mean ESR result for each patient, and emphasises the lack of agreement between the two methods.

\section{Discussion}

In a recent review on giant cell arteritis, Keltner ${ }^{11}$ pointed out that the incidence of headache varied from $4 \%$ to $100 \%$, temporal artery tenderness from $28 \%$ to $91 \%$, fever from $30 \%$ to $100 \%$ and jaw claudication from $4 \%$ to $67 \%$. This wide variability of signs and symptoms presents the clinician with diagnostic difficulties, especially in the elderly population, where giant cell arteritis can mimic many different diseases. The measurement of ESR is an important investigation in the diagnosis and monitoring of treatment.
Because the ESR is a non-specific test of the acute and chronic phase response, ${ }^{12}$ investigators have searched for more specific tests to complement or replace it. These have generally involved the laboratory measurement of individual acute phase proteins, including C-reactive protein, orosomucoid, serum amyloid A, caeruloplasmin, fibrinogen ${ }^{12}$ and anticardiolipin antibodies. ${ }^{13}$ Of these, C-reactive protein has shown most promise as it becomes elevated by as much as 600 -fold ${ }^{2}$ within $4-6 \mathrm{~h}$ after an insult. After the insult is removed, levels fall rapidly, usually within hours. ${ }^{12}$ In comparison ESR levels take a number of days to become elevated and take a similar time to return to normal. ${ }^{13}$ Because of this difference in time profile the tests should be seen as complementary and not mutually exclusive. ${ }^{2}$

Hayreh $^{2}$ found that in cases of biopsy-proven giant cell arteritis the ESR had a sensitivity and specificity of $92 \%$ ( $8 \%$ of patients had a normal ESR). In contrast, C-reactive protein measurement in men had a sensitivity and specificity of $100 \%$ and $83 \%$ respectively, while in women the values were $100 \%$ and $79 \%$ respectively. When the ESR and C-reactive protein results were combined, a specificity of $97 \%$ was found. Hayreh also found that an ESR value between 47 and 107 had an odds ratio of 1.4 for a positive temporal artery biopsy. In comparison, a C-reactive protein above $24.5 \mathrm{mg} / 1 \mathrm{had}$ an odds ratio of 3.2. Overall he found C-reactive protein to be superior to the ESR in the diagnosis of giant cell arteritis.

Despite this, ESR currently remains a commonly performed and important blood test in the investigation of giant cell arteritis, mainly because of its simplicity. The method used for its assessment needs to be accurate, reliable and rapid. The Seditainer system currently used in our eye casualty department meets some of the criteria but takes $1 \mathrm{~h}$ to perform and is not automated. The new automated method uses an automatic tube reader and an algorithm to produce results that are claimed to be 
equivalent to the ICSH. Westergren reference method within 25 min. ${ }^{8}$ We decided to investigate the new automated system with a view to replacing our current manual method.

While there appears to be a linear relationship between the two methods, there was a large degree of scatter which increased with the level of ESR. It is of concern that there were seven results which were markedly elevated when measured by the manual method but were classified as being within the normal range by the automated method. The difference was considered to be clinically significant. This means that there is a risk of misdiagnosis which may have sightthreatening consequences. The reason for the discrepant results is unknown, but repeat venesection and analysis revealed the automated result to be inconsistent.

It is known that the ESR is affected by factors such as packed cell volume and plasma albumin, globulin and fibrinogen concentrations. ${ }^{12}$ In the case of our patients, it is unlikely that the concentrations of these components would change in the space of a few hours before another blood sample could be taken. More importantly, the Seditainer results were reproduced in the repeated blood sample. One must assume, therefore, that the error occurred at either the venesection, mixing or transit stage or at the time of analysis.

Previous studies have shown that a loss of vacuum in the tube leading to an underfilling of the sample bottle by $80 \%$ causes a small reduction of the measured ESR, while loss of anticoagulant by leakage or poor quality control causes an overestimation of the ESR. ${ }^{6}$ Importantly, it has also been shown that ESR results are stable in blood stored for up to $20 \mathrm{~h}$ after venepuncture. ${ }^{6,8}$ Significantly, there were no falsely low results produced by the Seditainer method, making sample collection error an unlikely cause for the discrepant results.

Because there is no visual confirmation of results produced by the automated system, an error with the photocell reading of the plasma/red cell interface would be unlikely to be detected and an erroneous result could be reported.

The overall negative bias of the automated system and the wide scatter of results means that results above approximately $65 \mathrm{~mm} / \mathrm{h}$ can only be classified as semiquantitative. Using the Seditainer system, a result at the diagnostically important level of $50 \mathrm{~mm} / \mathrm{h}$ would have an approximately $95 \%$ chance of falling within the range 5 to $76 \mathrm{~mm} / \mathrm{h}$. The authors feel that this level of agreement is clinically unacceptable. Taken together with the risk of the new method significantly underestimating the true result, replacement of the manual Seditainer system with the new automated system in the eye casualty department cannot be recommended at the present time.

The authors would like to thank Miss P. Desai for her assistance with the data analysis and Mrs P. Simons for her assistance with the collection and analysis of the blood samples.

\section{References}

1. Gabay C, Kushner I. Acute phase proteins and other systemic responses to inflammation. N Engl J Med 1999;340:448-54.

2. Hayreh SS, Podhajsky PA, Raman R, Zimmerman B. Giant cell arteritis: validity and reliability of various diagnostic criteria. Am J Ophthalmol 1997;123:285-96.

3. Fernandez-Herlihy L. Temporal arteritis: clinical aids to diagnosis. J Rheumatol 1988;15:1797-801.

4. Hunder GG, Bloch DA, Beat AM, Stevens MB, Arend WP, Calabrese LH, et al. The American College of Rheumatology 1990 criteria for the classification of giant cell arteritis. Arthritis Rheum 1990;33:1122-9.

5. Westergren A. Studies of the suspension stability of the blood in pulmonary tuberculosis. Acta Med Scand 1921;54:247-82.

6. Patton WN, Meyer PJ, Stuart J. Evaluation of sealed vacuum extraction method (Seditainer) for the measurement of eryhthrocyte sedimentation rate. J Clin Pathol 1989;42:313-7.

7. Hurd C, Knight T. Laboratory evaluation of the Seditainer ESR system. Becton Dickinson, Between Towns Road, Cowley, Oxford, UK: 1986.

8. Imafuku Y, Yoshida H, Greenfield S, Rabinovitch A. Automated measurement of erythrocyte sedimentation rate and its relation to red cell concentration and plasma proteins. Hematol Cell Ther 1998;40:27-32.

9. Harvey PA, Tandon R, Singh AK. Automated ESR analysis in 20 min. Br J Ophthalmol 1995;79:396.

10. Bland JM, Altman DG. Statistical methods for assessing agreement between two methods of clinical measurement. Lancet 1986;I:307-10.

11. Keltner JL. Giant cell arteritis signs and symptoms. Ophthalmology 1982;89:1101-10.

12. International Committee for Standardisation in Haematology. Guidelines on selection of laboratory tests for monitoring the acute phase response. J Clin Pathol 1988;41:1203-12.

13. Manna R, Latteri M, Cristiano G, Todaro L, Scuderi F, Gasbarrini G. Anticardiolipin antibodies in giant cell arteritis and polymyalgia rheumatica: a study of 40 cases. $\mathrm{Br} \mathrm{J}$ Rheumatol 1998;37:208-10.

14. Kyle V. Laboratory investigations including liver in polymyalgia rheumatica/giant cell arteritis. Ballieres Clin Rheumatol 1991;5:475-85. 